\title{
Assessment of Target definition based on Multimodality Imaging for Radiosurgical Management of Glomus Jugulare Tumors (gjts)
}

\author{
Selcuk Demiral*, Omer Sager, Ferrat Dincoglan, Murat Beyzadeoglu \\ Department of Radiation Oncology; University of Health Sciences, Gulhane Medical Faculty, Ankara, Turkey
}

Submission: November 11, 2019; Published: December 12, 2019

"Correspondence Author: Selcuk Demiral, University of Health Sciences, Gulhane Medical Faculty, Department of Radiation Oncology, Gn.Tevfik Saglam Cad. 06018, Etlik, Kecioren, Ankara, Turkey

Abstract

Background: Glomus jugulare tumors (GJTs), also referred to as chemodectomas or paragangliomas are typically benign, highly vascular tumors which are derived from the paraganglionic cells. While surgery is typically utilized as the primary mode of management, complete surgical removal may not be feasible for selected patients due to critical location of some GJTs in close vicinity of vital neurovascular structures. In this context, radiosurgery offers an alternative or complementary noninvasive treatment for GJTs. Accurate target definition is a rule of thumb in precision radiosurgical treatments. While treatment planning is mostly performed by using Computed Tomography (CT) simulation in several departments of radiation oncology, additional imaging data from multimodality imaging may be exploited to tailor and refine optimal target determination for radiosurgery.

Objective: In this study, we assessed the use of multimodality imaging in target definition for SRS of GJTs.

Methods: Radiosurgery target volume definition was performed by using CT-simulation images only or by using both CT-simulation images and fused MR images for comparative evaluation. Ground truth target volume for actual treatment and comparative assessment was determined after comprehensive evaluation, colleague peer review, collaboration and consensus of the treatment team.

Results: Radiosurgery target volume definition based on CT only imaging and CT-MR fusion based imaging was assessed for 17 patients receiving SRS for GJTs at our institution. Mean target volume was found to be $6.8 \mathrm{cc}$ (range: 1.1-21.9 cc) on CT-only imaging and 7.2 cc (range: 1.2-22.1 cc) on CT-MR fusion based imaging. Target volumes generated by using CT-MR fusion based imaging were identical to target volumes generated by consensus decision of the treating team for the majority of patient group.

Conclusion: Incorporation of MRI may offer improved target definition for SRS of GJTs. Clearly, future studies are warranted to investigate the utility of multimodality imaging for GJT radiosurgery.

Keywords: Glomus jugulare tumor (GJT); Stereotactic radiosurgery (SRS); Computed tomography (CT); Magnetic resonance imaging (MRI); Target volume definition; Treatment planning; Radiosurgery

\section{Introduction}

Glomus jugulare tumors (GJTs), also referred to as chemodectomas or paragangliomas are typically benign, highly vascular tumors which are derived from the paraganglionic cells [1-5]. While GJTs arise from the glomus bodies found along the Jacobson nerve (tympanic branch of the glossopharyngeal nerve) or Arnold nerve (auricular branch of the vagus nerve) located within the jugular foramen, glomus tympanicum tumors arise from glomus bodies found along the Jacobson nerve located within the middle ear and cochlear promontory. These rare and highly vascular tumors typically follow an indolent disease course with a low tendency for metastatic spread, however, a wide spectrum of symptoms including pulsatile tinnitus, otalgia, ear fullness, headache, vertigo, dizziness, dysphagia, dysphonia, conductive or sensorineural hearing loss may occur in the setting of mass effect or invasion of nearby critical structures such as the internal carotid artery, jugular bulb, or lower cranial nerves [1-6].

Symptoms of GJTs may cause substantial deterioration in the affected patients' quality of life and may warrant prompt management for alleviation or elimination of these symptoms. While surgery is typically utilized as the primary mode of management, complete surgical removal may not be feasible for selected patients due to critical location of some GJTs in close 


\section{Cancer Therapy \& Oncology International Journal}

vicinity of vital neurovascular structures. In this context, radiation therapy offers a complementary or alternative treatment strategy for management of GJTs. Radiosurgical treatments in the forms of Stereotactic Radiosurgery (SRS), Fractionated Stereotactic Radiotherapy (FSRT), Hypofractionated Stereotactic Radiotherapy (HFSRT), and Stereotactic Body Radiation Therapy (SBRT) delivering high doses in one or a few treatment sessions have been utilized for management of several vascular disorders, functional disorders, malignant and benign tumors throughout the human body with encouraging therapeutic outcomes thanks to robust immobilization, precise target definition and treatment delivery under image guidance [1-4,7-23]. This contemporary treatment technique has been increasingly used as a noninvasive outpatient procedure with a condensed treatment schedule offering earlier return of patients to their daily activities.

Steep dose gradients around the radiosurgical target typically provides improved sparing of surrounding normal tissues, which is a prerequisite for radiation treatments delivering high fractional doses. In this context, accurate target definition is a rule of thumb in precision radiosurgical treatments [24]. While treatment planning is mostly performed by using Computed Tomography (CT) simulation in several departments of radiation oncology, additional imaging data from multimodality imaging may be exploited to tailor and refine optimal target determination for radiosurgery. In this study, we assessed the use of multimodality imaging in target definition for SRS of GJTs.

\section{Methods}

Seventeen patients treated with SRS for GJTs after thorough multidisciplinary assessment were included in the study. After affixing of a stereotactic head frame to the patients' skull under local anesthesia, CT-simulation was performed at the CT simulator (GE Lightspeed RT, GE Healthcare, Chalfont St. Giles, UK) available at our institution for acquisition of planning CT images. Image data sets of the patients were then transferred to the contouring Workstation (SimMD, GE, UK) via the network for target volume and critical organ delineation. All patients also had T1 gadoliniumenhanced Magnetic Resonance Imaging (MRI) typically acquired the day before SRS. Radiosurgery target volume definition was performed by using CT-simulation images only or by using both CT-simulation images and fused MR images for comparative evaluation. Ground truth target volume for actual treatment and comparative assessment was determined after comprehensive evaluation, colleague peer review, collaboration and consensus of the board-certified treatment team. ERGO ++ (CMS, Elekta, UK) radiosurgery planning system and Synergy (Elekta, UK) Linear Accelerator (LINAC) were used for treatment planning and delivery, respectively.

Visualization of the target and criticl structures was optimized by adjusting the windows and levels of the planning CT simulation images. Coronal and sagittal images were also used together with the axial images to improve delineation of target and criticl structures. Arc Modulation Optimization Algorithm (AMOA) was used to achieve optimal target coverage and sparing of surrounding normal tissues. Median dose for SRS was $15 \mathrm{~Gy}$ (range: $10-20 \mathrm{~Gy}$ ) prescribed to the $85 \%-100 \%$ isodose line. Image guided radiation therapy techniques such as $\mathrm{kV}$-CBCT (kilovoltage Cone Beam CT) and XVI (X-ray Volumetric Imaging, Elekta, UK) system were used for setup verification and precision SRS delivery. Intravenous dexamethasone with $\mathrm{H} 2$-antihistamines was used routinely for all patients after completion of SRS.

Results

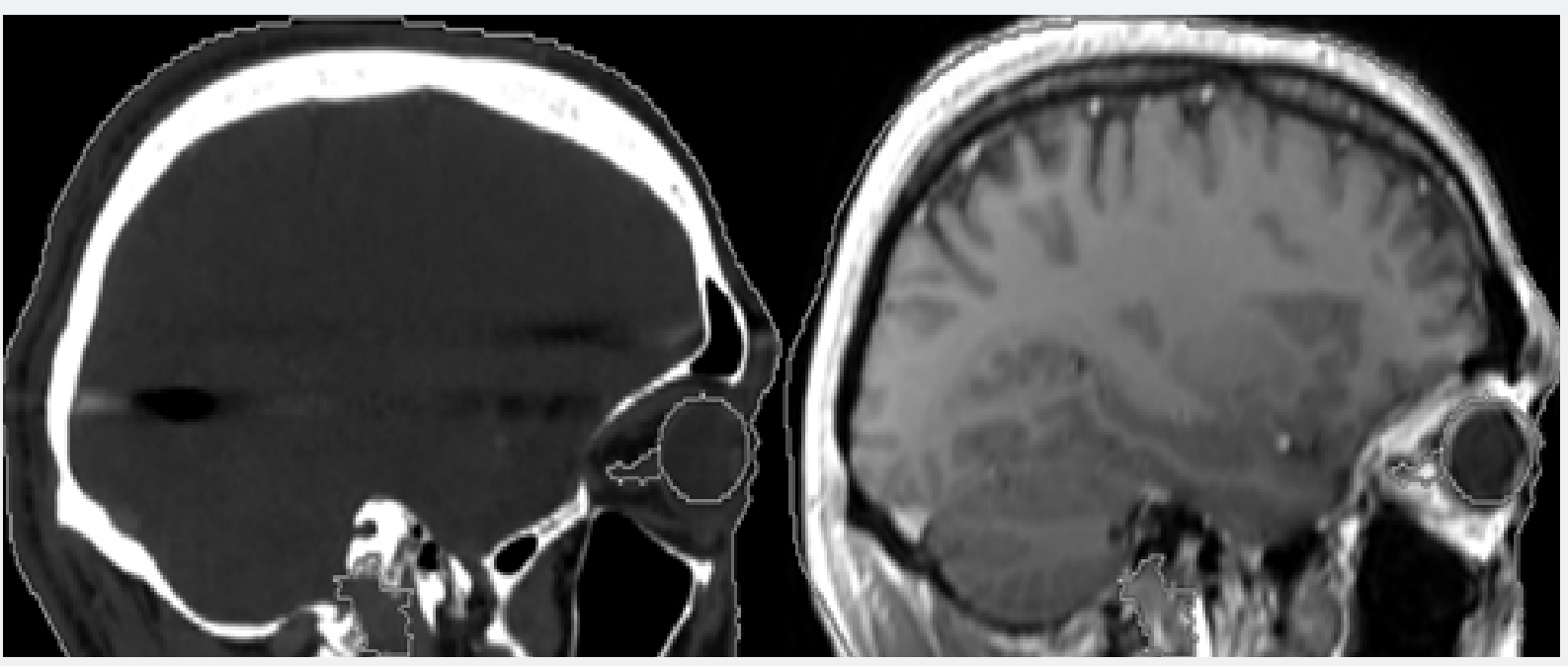

Figure 1: Sagittal planning CT and MR images of a patient with GJT. 


\section{Cancer Therapy \& Oncology International Journal}

Radiosurgery target volume definition based on CT only imaging and CT-MR fusion based imaging was assessed for 17 patients receiving SRS for GJTs at our institution. Mean target volume was found to be $6.8 \mathrm{cc}$ (range: 1.1-21.9 cc) on CT-only imaging and $7.2 \mathrm{cc}$ (range: 1.2-22.1 cc) on CT-MR fusion based imaging. Target volumes generated by using CT-MR fusion based imaging were identical to target volumes generated by consensus decision of the treating team for the majority of patient group. Figure 1 shows sagittal planning CT and MR images of a patient with GJT. In treatment planning for radiosurgery, we used five 180-degree arcs, a 360-degree arc, or double 360-degree arcs to achieve optimal target coverage whilst maintaining protection of normal tissues. All patients received high precision SRS using a LINAC with $6 \mathrm{MV}$ photons.

\section{Discussion}

Although rare, GJTs may lead to significant deterioration of the affected patients' health status and overall quality of life by causing several symptoms depending on their association with vital neurovascular structures. Decision making for management of GJTs requires multidisciplinary and collaborative consideration of several factors such as patient's age, general health status, comorbidities and preferences, lesion size, location and association with critical neurovascular structures, symptoms, and logistical issues. Surgery is the standard treatment, however, excessive risk of surgical complications may be an important concern for selected patients. Radiosurgery offers an alternative or complementary noninvasive treatment for GJTs. Several series, reviews and metaaalyses reported its safety and efficacy [1-4,2531].

GJTs may be regarded as ideal targets for radiosurgical management given their well-defined visualization. The use of SRS for management of GJTs is increasing rapidly with the growing body of evidence supporting its safety and efficacy. A favorable toxicity profile may be achieved by use of contemporary imaging techniques providing precise targeting and avoidance of excessive normal tissue exposure. Nevertheless, radiosurgical treatments delivering high fractional doses require utmost precision in target definition to avoid treatment failure and excessive normal tissue toxicities. In this aspect, multimodality imaging may aid in accurate target determination for radiosurgical management of GJTs. While CT provides valuable imaging information regarding the bony anatomy, incorporation of MRI confers additional imaging data which may facilitate contouring of the target and critical structures. Our study supports the use of MRI in addition to CT-simulation images in target definition for SRS of GJTs. In conclusion, incorporation of MRI may offer improved target definition for SRS of GJTs. Clearly, future studies are warranted to investigate the utility of multimodality imaging for GJT radiosurgery.

\section{Conflict of Interest}

There are no conflicts of interest and no acknowledgements.

\section{References}

1. Sager O, Beyzadeoglu M, Dincoglan F, Gamsiz H, Demiral S, et al. (2014) Evaluation of linear accelerator-based stereotactic radiosurgery in the management of glomus jugulare tumors. Tumori 100(2): 184-188.

2. Hafez RFA, Morgan MS, Fahmy OM (2016) An intermediate term benefits and complications of gamma knife surgery in management of glomus jugulare tumor. World J Surg Oncol 14(1): 36.

3. Sager O, Dincoglan F, Beyzadeoglu M (2015) Stereotactic radiosurgery of glomus jugulare tumors: current concepts, recent advances and future perspectives. CNS Oncol 4(2): 105-114.

4. Miller JP, Semaan MT, Maciumas RJ, (2009) Radiosurgery for glomus jugulare tumors. Otolaryngol Clin North Am 42(4): 689-706.

5. Forbes JA, Brock AA, Ghiassi M, Thompson RC, Haynes DS, et al. (2012) Jugulotympanic paragangliomas: 75 years of evolution in understanding. Neurosurg Focus 33(2): E13.

6. Brewis C, Bottrill ID, Wharton SB, Moffat DA et al. (2000) Metastases from glomus jugulare tumours. J Laryngol Otol 114(1): 17-23.

7. Demiral S, Dincoglan F, Sager O, et al. Contemporary Management of Meningiomas with Radiosurgery. Int J Radiol Imaging Technol 4(2): 041 .

8. Dincoglan F, Sager O, Demiral S, Bora Uysal, Hakan Gamsiz, et al. Radiosurgery for recurrent glioblastoma: a review article. Neurol Disord Therap 1(4): 1-5.

9. Demiral S, Dincoglan F, Sager O, Gamsiz H, Uysal B et al. (2016) Hypofractionated stereotactic radiotherapy (HFSRT) for who grade I anterior clinoid meningiomas (ACM). Jpn J Radiol 34(11): 730-737.

10. Dincoglan F, Beyzadeoglu M, Sager O, Demiral S, Gamsiz H, et al. (2015) Management of patients with recurrent glioblastoma using hypofractionated stereotactic radiotherapy. Tumori 101(2): 179-184.

11. Gamsiz H, Beyzadeoglu M, Sager O, Demiral S, Dincoglan F, et al. (2015) Evaluation of stereotactic body radiation therapy in the management of adrenal metastases from non-small cell lung cancer. Tumori 101(1): 98-103.

12. Demiral S, Beyzadeoglu M, Sager O (2014) Evaluation of Linear Accelerator (Linac)-Based Stereotactic Radiosurgery (Srs) for The Treatment of Craniopharyngiomas. Int J Hematol Oncol 24(2): 123129.

13. Gamsiz H, Beyzadeoglu M, Sager O, Dincoglan F, Demiral S et al Management of pulmonary oligometastases by stereotactic body radiotherapy. Tumori 100(2): 179-183.

14. Sager O, Beyzadeoglu M, Dincoglan F, Uysal B, Gamsiz H, et al. (2014) Evaluation of linear accelerator (LINAC)-based stereotactic radiosurgery (SRS) for cerebral cavernous malformations: a 15-year single-center experience. Ann Saudi Med 34(1): 54-58.

15. Dincoglan F, Sager O, Gamsiz H, Uysal B, Demiral S, et al. (2014) Management of patients with $\geq 4$ brain metastases using stereotactic radiosurgery boost after whole brain irradiation. Tumori 100(3): 302306.

16. Sager O, Beyzadeoglu M, Dincoglan F, Demiral S, Uysal B, et al. (2013) Management of vestibular schwannomas with linear acceleratorbased stereotactic radiosurgery: a single center experience. Tumori 99(5): 617-622. 


\section{Cancer Therapy \& Oncology International Journal}

17. Dincoglan F, Beyzadeoglu M, Sager O, Uysal B, Demiral S, et al. (2013) Evaluation of linear accelerator-based stereotactic radiosurgery in the management of meningiomas: a single center experience. J BUON 18(3): 717-722

18. Demiral S, Beyzadeoglu M, Uysal B, Oysul K, Kahya YE, et al. (2013) Evaluation of stereotactic body radiotherapy (SBRT) boost in the management of endometrial cancer. Neoplasma 60(3): 322-327.

19. Dincoglan F, Sager 0, Gamsiz H, Selcuk Demiral, Bora Uysal, et al (2019) Management of Arteriovenous Malformations by Stereotactic Radiosurgery: A Single Center Experience. Int J Hematol Oncol 22(2) 107-112.

20. Dincoglan F, Sager O, Gamsiz H, et al. (2012) Stereotactic radiosurgery for intracranial tumors: a single center experience. Gulhane Med J 54(3): 190-198.

21. Dincoglan F, Beyzadeoglu M, Sager O, Oysul K, Sirin S, et al. (2012) Image-guided positioning in intracranial non-invasive stereotactic radiosurgery for the treatment of brain metastasis. Tumori 98(5): 630-635.

22. Surenkok S, Sager O, Dincoglan F, Hakan Gamsız, Selcuk Demiral, et al. (2012) Stereotactic radiosurgery in pituitary adenomas: a single center experience. Int J Hematol Oncol 22(4): 255-260.

23. Sirin S, Oysul K, Surenkok S, Sager O, Dincoglan F, et al. (2011) Linear accelerator-based stereotactic radiosurgery in recurrent glioblastoma: a single center experience. Vojnosanit Pregl 68(11): 961-966.

24. Demiral S, Sager O, Dincoglan F, Uysal B, Gamsiz H, et al. (2018) Evaluation of Target Volume Determination for Single Session
Stereotactic Radiosurgery (SRS) of Brain Metastases. Canc Therapy \& Oncol Int J 12(5): 555848.

25. Ivan ME, Sughrue ME, Clark AJ, Kane AJ, Aranda D, et al. (2011) A metaanalysis of tumor control rates and treatment-related morbidity for patients with glomus jugulare tumors. J Neurosurg 114(5): 1299-1305.

26. Guss ZD, Batra S, Limb CJ, Li G, Sughrue ME, et al. (2011) Radiosurgery of glomus jugulare tumors: a meta-analysis. Int J Radiat Oncol Biol Phys 81(4): e497-502.

27. Lieberson RE, Adler JR, Soltys SG, Choi C, Gibbs IC, et al. (2012) Stereotactic radiosurgery as the primary treatment for new and recurrent paragangliomas: is open surgical resection still the treatment of choice? World Neurosurg 77(5-6): 745-761.

28. Sallabanda K, Barrientos H, Isernia Romero DA, Vargas C, Gutierrez Diaz JA, et al. (2018) Long-term outcomes after radiosurgery for glomus jugulare tumors. Tumori 104(4): 300-306.

29. Gigliotti MJ, Hasan S, Liang Y, Chen D, Fuhrer R et al. (2018) A 10year experience of linear accelerator-based stereotactic radiosurgery/ radiotherapy(SRS/SRT) for paraganglioma: A single institution experience and review of the literature. J Radiosurg SBRT 5(3): 183190.

30. Winford TW, Dorton LH, Browne JD, et al. (2017) Stereotactic Radiosurgical Treatment of Glomus Jugulare Tumors. Otol Neurotol 38(4): 555-562.

31. Ibrahim R, Ammori MB, Yianni J, Grainger A, Rowe J, et al. (2017) Gamma Knife radiosurgery for glomus jugulare tumors: a single-center series of 75 cases. J Neurosurg 126(5): 1488-1497.

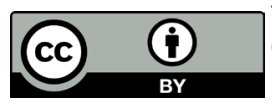

This work is licensed under Creative Commons Attribution 4.0 License DOI: 10.19080/CTOIJ.2019.15.555909

\section{Your next submission with Juniper Publishers} will reach you the below assets

- Quality Editorial service

- Swift Peer Review

- Reprints availability

- E-prints Service

- Manuscript Podcast for convenient understanding

- Global attainment for your research

- Manuscript accessibility in different formats

( Pdf, E-pub, Full Text, Audio)

- Unceasing customer service

Track the below URL for one-step submission https://juniperpublishers.com/online-submission.php 